\title{
Influenza mortality among the elderly in France, 1980-90: how many deaths may have been avoided through vaccination?
}

\author{
Fabrice Carrat, Alain-Jacques Valleron
}

\begin{abstract}
Study objectives - This study aimed to assess total influenza mortality among the elderly ( $\geq 75$ years old) in France, and to evaluate how many deaths may have been avoided through vaccination during the past 10 years.

Design - The monthly mortality rates related to different causes among the elderly were obtained from the national mortality statistics for the period 1978-90. For each cause, the proportion of the registered death rate attributable to influenza was estimated using time series models. Each model analysed the registered death rate for the considered cause as a linear function of the registered influenza death rate for that month, the secular trend, and the seasonal variations. This yielded yearly regression coefficients for influenza. Formulas were subsequently developed to estimate the death rates avoided as a result of influenza vaccination according to the level of vaccine coverage and the hypothetical effectiveness of the vaccine.
\end{abstract}

Main results - Between 1980 and 1990 registered influenza death rates ranged from 11-81 per 100000 . The number of deaths attributable to influenza but registered as resulting from another cause was up to eight times the number of deaths registered as influenza. Total influenza death rates were estimated as ranging from 28 per $100000(1988-89)$ to 482 per 10000 (1985-86). At the same time it was estimated that the use of influenza vaccine avoided from 7 per 100000 deaths in 1981-82 to 697 per 100000 deaths in 198990 , depending on the intensity of the epidemic, the vaccine coverage, and the vaccine effectiveness.

Conclusions - These results support the policy of promoting influenza vaccination among the elderly.

\section{(f Epidemiol Community Health 1995;49:419-425)}

Elderly people are the main victims of influenza as far as mortality is concerned. ${ }^{1-10}$ For example, during the winter of 1989-90 in France, $88 \%$ of the death certificates registered as ICD9 487 (influenza) concerned people aged 75 years or more. The diagnosis entered on the death certificate is in general poorly validated, however, particularly with regard to influenza, where the virology is generally unknown to the reporting physician. Influenza is certainly not always recorded as the cause of death and therefore estimates of the actual number of deaths resulting from influenza require calculations of mortality attributable to influenza in other registered causes. ${ }^{1-810}$

The fact that influenza vaccination reduces the risk of severe medical complications and of death among the elderly is now supported by epidemiological evidence, despite estimates of vaccine effectiveness ranging from $40 \%$ to $90 \%,{ }^{911-16}$ depending on population subgroups, influenza virus, influenza vaccines, and antigenic similarities between wild and vaccine strains.

In recent years, a massive public health programme of influenza vaccination for the elderly has been adopted in France. Since 1985, the National Social Security System has provided all people aged 75 or more with free inactivated trivalent vaccine. (In 1988, free vaccination was extended to all people aged 70 or more and to people suffering from seven underlying chronic conditions.) Free vaccination has also been offered to all those with immunodeficiency conditions, including AIDS, since 1990.) In 1991, 74\% of the population aged 75 or more were vaccinated, mainly thanks to a massive publicity campaign.

In this study we have used a statistical model to assess total influenza mortality among the elderly in France and to estimate how many deaths have been avoided by influenza vaccination over the past 10 years.

\section{Data and methods}

DATA

The number of deaths per month among people aged 75 years or more was obtained from the French National Centre of Mortality Statistics, (Service Commun 8, Institut National de la Santé et de la Recherche Médicale). The period studied was $1978-90$. Monthly mortality rates were computed for each cause of death based on population estimates derived from the national censuses of 1975, 1982, and 1990. Table 1 presents the basic information on the causes of death analysed. The ICD9 codes were selected on the basis of conditions documented as entailing the risk of death from influenza, particularly respiratory and cardiovascular diseases, diabetes mellitus, and chronic rental failure. ${ }^{29}$ Deaths from lung cancer, breast cancer, and cirrhosis and deaths from unknown or unspecified causes have also been considered. 
Table 1 Registered causes of death included in the analysis in subjects aged 75 years or more, France, $1978-90$.

\begin{tabular}{|c|c|c|c|}
\hline Causes of death & Code number (ICD9) & $\begin{array}{l}\text { Mean death rates per } \\
\text { month (per } 100000)\end{array}$ & $(S D)$ \\
\hline \multicolumn{4}{|l|}{ Respiratory diseases: } \\
\hline Influenza & 487 & $2 \cdot 9$ & $(5 \cdot 9)$ \\
\hline Pneumonia & $480-486$ & $17 \cdot 2$ & $(7 \cdot 9)$ \\
\hline Chronic obstructive pulmonary disease & $490-492,494,496$ & $19 \cdot 4$ & $(5 \cdot 1)$ \\
\hline Asthma & 493,495 & $2 \cdot 2$ & $(0 \cdot 6)$ \\
\hline Other respiratory diseases & others between $460-519$ & $19 \cdot 8$ & $(9 \cdot 0)$ \\
\hline \multicolumn{4}{|l|}{ Cardiovascular diseases: } \\
\hline Chronic rheumatic disease & $390-398$ & $1 \cdot 2$ & $(0 \cdot 3)$ \\
\hline Hypertensive disease & $401-405$ & $9 \cdot 8$ & $(1.5)$ \\
\hline Ischaemic heart disease & $410-414$ & $74 \cdot 8$ & $(9 \cdot 8)$ \\
\hline Other cardiopathy & $415-425$ & $14 \cdot 2$ & $(2 \cdot 2)$ \\
\hline Cardiac dysrhythmias & 426,427 & $19 \cdot 8$ & $(3 \cdot 0)$ \\
\hline Heart failure & 428,429 & 73.4 & $(15 \cdot 3)$ \\
\hline Cerebrovascular disease & $430-438$ & $110 \cdot 5$ & $(22 \cdot 0)$ \\
\hline Other heart diseases & others between $440-459$ & $29 \cdot 7$ & $(4 \cdot 5)$ \\
\hline Diabetes mellitus & 250 & $10 \cdot 8$ & $(1 \cdot 7)$ \\
\hline Chronic renal failure & $580-586$ & $10 \cdot 5$ & $(2 \cdot 4)$ \\
\hline Lung cancer & 162 & 13.4 & $(1 \cdot 3)$ \\
\hline Breast cancer & 174,175 & $8 \cdot 3$ & $(0 \cdot 9)$ \\
\hline Cirrhosis & $571 \cdot 0,571 \cdot 3,571 \cdot 5$ & $4 \cdot 4$ & $(1 \cdot 0)$ \\
\hline Unspecified or unknown & $780-799$ & $53 \cdot 3$ & $(9 \cdot 3)$ \\
\hline \multicolumn{4}{|l|}{ Others: } \\
\hline Difference between total mortality and & All minus previous & $255 \cdot 5$ & $(19 \cdot 6)$ \\
\hline Total mortality & All & $751 \cdot 1$ & $(102 \cdot 8)$ \\
\hline
\end{tabular}

Finally, we defined "others" as the difference between total registered mortality rates and all the previously enumerated death rates. This aggregated variable represented a set of conditions not known to entail the risk of death from influenza.

Vaccine coverage data were obtained from surveys on representative samples of the population 75 years old or older during the winters of 1981-82, 1982-83, 1983-84, 1986-87, 1988-89, and 1989-90 (unpublished data from SOFRES/GEIG).

For epidemic purposes, each annual study period was defined as beginning in October and finishing in September.

\section{METHOD}

Estimation of the total influenza death rates

Let us consider the death rate from a given cause (for example pneumonia), registered in a given month $(t)$, of a year $(y)$. Our first objective was to estimate the proportion of the pneumonia death rate that might be attributable to influenza.

General description. The estimation and testing of a relationship between two variables is classically done by regression methods. In most cases, these methods assume that the observed data are realisations of independent random variables. If data which arise in a time sequence have to be analysed, however, consecutive observations may be dependent. A high monthly mortality rate for a given cause is also more likely to be high one month after or before (positive autocorrelation).

Another problem arises when both variables have some seasonal pattern in common. These common features will act as a confounder and will probably lead to a significant association between the two variables. Such an association cannot be interpreted as suggesting a direct link between them, however, since it may only reflect the seasonal pattern of a common predisposing factor. Therefore, in these cases regression methods must be adapted to make full use of the time pattern of the variables while giving correct estimates and test statistics. By using the "Box-Jenkins" approach, it becomes possible to assess the relations between two time series (the registered pneumonia death rate as the dependent variable and the registered influenza death rate as the explanatory variable) by incorporating non-explanatory statistical time series components in a regression model (regression models with autoregressive integrated moving average (ARIMA) errors). These models incorporated the temporal modelled terms that dealt with serial correlations of residuals, and the confounding effects of trend and seasonality. It would not be appropriate to include a detailed description of the ARIMA models in this paper. Instead the reader is requested to refer to various articles, ${ }^{617-21}$ which summarise the approach or give examples of its application. In the following section an adapted regression model with ARIMA errors is briefly presented through the example of pneumonia.

Detailed description. Let $Y_{t}$ denote the registered pneumonia death rate in month $t$. This rate was considered to be composed of two terms,

$$
Y_{t}=X_{t}+N_{t}
$$

$X_{t}$ was the part which may be explained in terms of the registered influenza death rate $\left(I_{t}\right)$ and $N_{t}$ was an error or noise process, which describes the unexplained part of $Y_{t}$. It was assumed that $X_{\mathrm{t}}$, which represents the part of mortality attributable to influenza, was proportional to $I_{t}$

$$
X_{t}=\beta I_{t}
$$

We have estimated a different $\beta$ for each year to account for the variability of the underlying influenza epidemic. Equation (2) may be written under its general form as:

$X_{t}=\beta_{y} I_{t, y}$, with $I_{t, y}=I_{t}$ if $t \in y ; I_{t, y}=0$ elsewhere

Then the final model was

$$
Y_{t}=\beta_{y} I_{t, y}+N_{t}
$$

and $N_{\mathrm{t}}$ was described by an ARIMA process. 
Table 2 Example of results from regression model that included autoregressive integrated moving average errors: death rates attributable to influenza and registered as pneumonia (ICD9 480-486).

\begin{tabular}{|c|c|c|c|c|c|c|c|c|c|c|}
\hline \multirow{3}{*}{ Year* } & \multirow{3}{*}{$\begin{array}{l}\text { Parameter } \\
\text { estimates } \\
\left(\hat{\beta}_{y}\right)+\end{array}$} & \multirow{3}{*}{$(S E)$} & \multirow{3}{*}{$\begin{array}{l}\text { Registered } \\
\text { influenza } \\
(\text { per } 100000) \\
\left(\sum_{t=1}^{12} I_{t, y}\right)\end{array}$} & \multirow{3}{*}{$\begin{array}{l}\text { Registered } \\
\text { pneumonia } \\
\text { (per 100000) } \\
\left(\sum_{t=1}^{12} Y_{t, y}\right)\end{array}$} & \multicolumn{6}{|c|}{ Predicted pneumonia death rate (per 100000 ) } \\
\hline & & & & & Total & $(95 \% C I)$ & $\begin{array}{l}\text { Attrib } \\
\text { to inf }\end{array}$ & $(95 \% C I)$ & Unexplained $\ddagger$ & $(95 \% C I)$ \\
\hline & & & & & \multicolumn{2}{|l|}{$\left(\sum_{t=1}^{12} \hat{Y}_{t, v}\right) \dagger$} & \multicolumn{2}{|c|}{$\left(\sum_{t=1}^{12} \hat{\beta}_{y} I_{t, v}\right)$} & \multicolumn{2}{|l|}{$\left(\sum_{t=1}^{12} \hat{N}_{t, y}\right) \dagger$} \\
\hline $1980 / 81$ & $0 \cdot 38$ & $(0 \cdot 05)$ & $81 \cdot 2$ & $156 \cdot 3$ & $147 \cdot 2$ & $(92,203)$ & $30 \cdot 7$ & $(23,39)$ & 116.5 & $(69,164)$ \\
\hline $1981 / 82$ & NS & - & $16 \cdot 1$ & 135.9 & $131 \cdot 4$ & $(80,183)$ & - & & $131 \cdot 4$ & $(80,183)$ \\
\hline $1982 / 83$ & $0 \cdot 28$ & $(0 \cdot 07)$ & $57 \cdot 0$ & $161 \cdot 6$ & $157 \cdot 1$ & $(108,206)$ & $16 \cdot 1$ & $(8,24)$ & $141 \cdot 0$ & $(100,182)$ \\
\hline $1983 / 84$ & NS & & $16 \cdot 3$ & $157 \cdot 4$ & $154 \cdot 7$ & $(106,203)$ & - & & $154 \cdot 7$ & $(106,203)$ \\
\hline $1984 / 85$ & 0.78 & $(0 \cdot 13)$ & 34.9 & $249 \cdot 2$ & $239 \cdot 2$ & $(191,287)$ & $27 \cdot 3$ & $(18,36)$ & 211.9 & $(173,251)$ \\
\hline $1985 / 86$ & $1 \cdot 14$ & $(0 \cdot 07)$ & 53.9 & $306 \cdot 2$ & $302 \cdot 8$ & $(255,350)$ & $61 \cdot 7$ & $(54,69)$ & $241 \cdot 1$ & $(201,281)$ \\
\hline $1986 / 87$ & 1.63 & $(0 \cdot 50)$ & $11 \cdot 0$ & 255.8 & $264 \cdot 3$ & $(217,311)$ & $18 \cdot 0$ & $(7,29)$ & $246 \cdot 3$ & $(210,282)$ \\
\hline $1987 / 88$ & $1 \cdot 30$ & $(0 \cdot 34)$ & 14.5 & $251 \cdot 2$ & 253.0 & $(206,300)$ & 18.9 & $(9,29)$ & $234 \cdot 1$ & $(197,271)$ \\
\hline $1988 / 89$ & 0.54 & $(0.21)$ & $18 \cdot 3$ & 249.9 & $252 \cdot 3$ & $(205,299)$ & 9.9 & $(2,17)$ & $242 \cdot 4$ & $(203,272)$ \\
\hline $1989 / 90$ & 0.59 & $(0.05)$ & 68.9 & 271.9 & $277 \cdot 2$ & $(230,324)$ & $40 \cdot 7$ & $(34,47)$ & $236 \cdot 5$ & $(196,277)$ \\
\hline
\end{tabular}

* Each yearly period began in October and finished in September.

+ Signs " indicate predicted values.

$\ddagger$ Unexplained part (noise process) was modelled with multiplicative moving average model of order $1($ parameter $=0 \cdot 69(0 \cdot 07))$ and $12($ parameter $=0 \cdot 84(0 \cdot 12)$ ).

The parameters were estimated by using the maximum likelihood method ${ }^{22}$ with the ARIMA procedure of the SAS/ETS software, and $t$ tests were calculated. The models were chosen on the basis of minimum residual error variance. The validity of the regression models was assessed by graphical residual analysis and by goodness of fit tests. ${ }^{23}$

The yearly death rate from the given cause (pneumonia) which can be attributed to influenza in year y was given by:

$$
\sum_{t=1}^{12} \hat{\beta}_{y} I_{t, y}
$$

(if $\hat{\beta}_{y}$ was significantly different from zero).

The yearly total influenza death rates were defined as the sum of yearly registered influenza death rates and the yearly rates for all other deaths attributable to influenza.

\section{Estimation of the death rates avoided through vaccination}

To evaluate the impact of the vaccination programme on mortality, different values of vac- cine effectiveness ranging from $40 \%$ to $90 \%$ were used. These values were the minimum and maximum ones found in studies covering vaccine effectiveness on mortality among the elderly. ${ }^{11-131516}$ Assuming that the attack rate of deaths from influenza among unvaccinated subjects does not depend on the level of vaccine coverage, we have estimated the death rates avoided through vaccination by the formula

$$
d_{a}=\frac{d_{o} p V E}{(1-p V E)}
$$

(see Appendix), where $d_{o}$ is the registered or total influenza death rate in a given year, $p$ is the vaccine coverage that year, and $\mathrm{VE}$ is the vaccine effectiveness.

\section{Results}

During the period 1980-90, the registered influenza death rates ranged from 11 per 100000 in 1986-87 to 81 per 100000 in 1980-81 (table 2 ). There were five high influenza mortality years: $1980-81,1982-83,1984-85,1985-86$ and 1989-90.

Table 3 Yearly influenza (ICD9 487) death rates (per 100 000) and yearly death rates (per 100 000) attributable to influenza for other causes of

\begin{tabular}{|c|c|c|c|c|c|c|c|c|c|c|c|c|c|c|c|c|c|c|c|}
\hline & \multicolumn{2}{|c|}{$1980 / 81$} & \multicolumn{2}{|c|}{$81 / 82$} & \multicolumn{2}{|l|}{$82 / 83$} & $83 / 84$ & \multicolumn{2}{|l|}{$84 / 85$} & \multicolumn{2}{|l|}{$85 / 86$} & \multicolumn{2}{|l|}{$86 / 87$} & \multicolumn{2}{|l|}{$87 / 88$} & \multicolumn{2}{|l|}{$88 / 89$} & \multicolumn{2}{|l|}{$89 / 90$} \\
\hline $\begin{array}{l}\text { Size of the population } \\
(\times 1000)\end{array}$ & 3177 & & 3249 & & 3325 & & 3401 & 3479 & & 3546 & & 3616 & & 3701 & & 3786 & & 4154 & \\
\hline $\begin{array}{l}\text { Total mortality rates } \\
\text { Registered influenza death }\end{array}$ & 9776 & & 9342 & & 9589 & & 9226 & 9239 & & 9254 & & 8560 & & 8430 & & 8351 & & 7829 & \\
\hline & $81 \cdot 2$ & & $16 \cdot 1$ & & 57.0 & & $16 \cdot 3$ & 34.9 & & 53.9 & & $11 \cdot 0$ & & $14 \cdot 5$ & & 18.3 & & $68 \cdot 9$ & \\
\hline Registered causes of death & \multicolumn{19}{|c|}{ Death rates attributable to influenza $(95 \% C I)$} \\
\hline $\begin{array}{l}\text { Pneumonia } \\
\text { Chronic obstructive }\end{array}$ & 30.7 & $(23,39)$ & $-t$ & & $16 \cdot 1$ & $(8,24)$ & - & $27 \cdot 3$ & $(18,36)$ & $61 \cdot 7$ & $(54,69)$ & $18 \cdot 0$ & $(7,29)$ & 18.9 & $(9,29)$ & 9.9 & $(2,17)$ & $40 \cdot 7$ & $(34,47)$ \\
\hline pulmonary disease & $20 \cdot 8$ & $(13,29)$ & - & & 12.5 & $(7,18)$ & - & $19 \cdot 8$ & $(14,26)$ & 35.9 & $(30,41)$ & - & & - & & - & & 33.1 & $(28,38)$ \\
\hline $\begin{array}{l}\text { Asthma } \\
\text { Other respiratory diseases }\end{array}$ & $\begin{array}{r}3 \cdot 0 \\
30 \cdot 3\end{array}$ & $(2,4)$ & - & & & & - & & & $3 \cdot 0$ & $(2,4)$ & - & & & & - & & $3 \cdot 8$ & $(3,5)$ \\
\hline $\begin{array}{l}\text { Other respiratory diseases } \\
\text { Hypertensive disease }\end{array}$ & & $(21,40)$ & - & & $39 \cdot 3$ & $(30,48)$ & $33 \cdot 3(16,51)$ & $17 \cdot 1$ & $(7,27)$ & 19.5 & $(11,28)$ & - & & - & & - & & $22 \cdot 3$ & $(15,30)$ \\
\hline $\begin{array}{l}\text { Hypertensive disease } \\
\text { Ischaemic heart disease }\end{array}$ & $\overline{14 \cdot 7}$ & $(4,26)$ & $=$ & & 19.6 & $(9,31)$ & $\because$ & 3.8 & $(1,7)$ & $4 \cdot 9$ & $(2,8)$ & - & & & & - & & $6 \cdot 0$ & $(4,9)$ \\
\hline Cardiac dysrhythmias & $8 \cdot 3$ & $(5,11)$ & - & & 13.0 & $\begin{array}{l}(10,16) \\
(10)\end{array}$ & $8.5(1,16)$ & $\begin{array}{r}27 \cdot 2 \\
8 \cdot 6\end{array}$ & $(15,39)$ & $39 \cdot 7$ & $(29,51)$ & - & & $14 \cdot 8$ & $(1,29)$ & - & & $29 \cdot 8$ & $(20,40)$ \\
\hline Heart failure & $47 \cdot 2$ & $(31,63)$ & & & $24 \cdot 7$ & $(10,40)$ & $-(1,10)$ & $\begin{array}{r}8 \cdot 6 \\
42 \cdot 3\end{array}$ & $\begin{array}{r}(5,12) \\
(26,59)\end{array}$ & $\begin{array}{l}15 \cdot 1 \\
48 \cdot 3\end{array}$ & $\begin{array}{l}(12,18) \\
(34,63)\end{array}$ & $9 \cdot 8$ & $(5,14)$ & - & & - & & $9 \cdot 0$ & $(7,11)$ \\
\hline Cerebrovascular disease & 37.5 & $(19,56)$ & & & 25.9 & $(8,43)$ & & $46 \cdot 7$ & $(27,66)$ & 59.0 & $(42,77)$ & - & & - & & - & & $\begin{array}{l}23 \cdot 2 \\
21 \cdot 0\end{array}$ & $\begin{array}{r}(10,37) \\
(3,39)\end{array}$ \\
\hline & - & & $\therefore$ & & 7.5 & $(4,11)$ & - & $4 \cdot 6$ & $(1,8)$ & $5 \cdot 7$ & $(2,9)$ & - & & * & & - & & $\begin{array}{r}1.0 \\
8.7\end{array}$ & $\begin{array}{l}(3,39) \\
(6,12)\end{array}$ \\
\hline $\begin{array}{l}\text { Diabetes mellitus } \\
\text { Chronic renal failure }\end{array}$ & $6 \cdot 4$ & $(4,8)$ & $10 \cdot 7$ & $(9,13)$ & $5 \cdot 7$ & $(4,8)$ & - & $\overline{6} \cdot 2$ & $(4,8)$ & $\begin{array}{l}6.2 \\
7.3\end{array}$ & $(3,9)$ & - & & - & & - & & 5.6 & $(3,9)$ \\
\hline Lung cancer & - & & $8 \cdot 3$ & $(2,14)$ & - & & - & -2 & $(4,8)$ & $\begin{array}{l}7.3 \\
3.5\end{array}$ & $(6,9)$ & $2 \cdot 6$ & $(0,5)$ & - & & $\overline{-}$ & & $\begin{array}{l}4.6 \\
3.4\end{array}$ & $(3,7)$ \\
\hline Undefined and unknown & $28 \cdot 2$ & $(16,40)$ & - & & $21 \cdot 1$ & $(8,34)$ & - & $26 \cdot 4$ & $(13,40)$ & $\begin{array}{r}3.5 \\
40.7\end{array}$ & $\begin{array}{c}(0,7) \\
(30,51)\end{array}$ & - & & - & & - & & $\begin{array}{r}3 \cdot 4 \\
22 \cdot 1\end{array}$ & $\begin{array}{l}(1,6) \\
(11,33)\end{array}$ \\
\hline Othersł & $58 \cdot 6$ & $(28,89)$ & & & $49 \cdot 2$ & $(20,79)$ & $68 \cdot 1(8,128)$ & $55 \cdot 2$ & $(22,89)$ & $77 \cdot 1$ & $(49,105)$ & - & & $44 \cdot 1$ & $(6,83)$ & - & & 76.6 & $(53,100)$ \\
\hline Total influenza death rates & 366.9 & $(247,486)$ & $35 \cdot 1$ & $(27,43)$ & $291 \cdot 6$ & $(175,409)$ & $126 \cdot 2(38,211)$ & $320 \cdot 1$ & $(188,452)$ & $481 \cdot 5$ & $(360,603)$ & $41 \cdot 4$ & $(23,59)$ & $92 \cdot 3$ & $(31,156)$ & $28 \cdot 2$ & $(20,35)$ & $378 \cdot 8$ & $(270,492)$ \\
\hline Total no of influenza deaths & & & & & & & & & & & & & & & & & & & \\
\hline$(\times 1000)$ & 11.7 & $(8,15)$ & $1 \cdot 1$ & $(0 \cdot 9,1 \cdot 4)$ & $9 \cdot 7$ & $(6,14)$ & $4 \cdot 3(1,7)$ & $11 \cdot 1$ & $(7,16)$ & $17 \cdot 1$ & $(13,21)$ & 1.5 & $(1,2)$ & $3 \cdot 4$ & $(1,6)$ & $1 \cdot 1$ & $(0 \cdot 8,1 \cdot 3)$ & 15.7 & $(11,20)$ \\
\hline
\end{tabular}
death among those aged 75 years or more, France 1980-90*

* Each yearly period began in October and finished in September

† Non significant regression coefficient.

$\ddagger$ Difference between total mortality rates and all the other listed causes of death in Table 1 . 




Figure 1 Death rates attributable to influenza and registered as pneumonia among people aged 75 years old or more, France, 1980-90. Example of the best fitted regression model with ARIMA errors. (---) Registered death rates; (upper $\longrightarrow$ ) predicted death rates; (lower-) predicted in the absence of influenza (unexplained part of the pneumonia death rates). The grey areas represent the part of the pneumonia death rate attributable to influenza.

\section{ESTIMATION OF THE TOTAL INFLUENZA DEATH RATES}

Table 2 gives an example of the best fitted regression model for the pneumonia death rate. The noise process (the unexplained part of pneumonia death rate) was modelled with a multiplicative moving average process of orders 1 and 12. Predicted values of pneumonia death

Table 4 Estimates of the registered influenza death rates per 100000 (ICD9 487) avoided through vaccination among the elderly $\left(d_{a}\right)$ for different rates of vaccine effectiveness

\begin{tabular}{|c|c|c|c|c|c|c|}
\hline \multirow[b]{2}{*}{ Year } & \multirow[b]{2}{*}{$d_{o}$} & \multirow[b]{2}{*}{$p$} & \multicolumn{4}{|c|}{ Vaccine effectiveness } \\
\hline & & & $\begin{array}{l}40 \% \\
d_{a}\end{array}$ & $\begin{array}{l}60 \% \\
d_{a} \\
\end{array}$ & $\begin{array}{l}80 \% \\
d_{a}\end{array}$ & $\begin{array}{l}90 \% \\
d_{a} \\
\end{array}$ \\
\hline $\begin{array}{l}1981 / 82 \\
1982 / 83 \\
1983 / 84 \\
1986 / 87 \\
1988 / 89 \\
1989 / 90\end{array}$ & $\begin{array}{l}16 \cdot 1 \\
57 \cdot 0 \\
16 \cdot 3 \\
11 \cdot 0 \\
18 \cdot 3 \\
68 \cdot 9\end{array}$ & $\begin{array}{l}0.43 \\
0.49 \\
0.58 \\
0.60 \\
0.66 \\
0.72\end{array}$ & $\begin{array}{r}3.3 \\
13.9 \\
4.9 \\
3.5 \\
6.6 \\
27.9\end{array}$ & $\begin{array}{r}5 \cdot 6 \\
23 \cdot 7 \\
8 \cdot 7 \\
6 \cdot 2 \\
12 \cdot 0 \\
52 \cdot 4\end{array}$ & $\begin{array}{r}8 \cdot 4 \\
36 \cdot 8 \\
14 \cdot 1 \\
10 \cdot 2 \\
20 \cdot 5 \\
93 \cdot 6\end{array}$ & $\begin{array}{r}10 \cdot 2 \\
45 \cdot 0 \\
17 \cdot 8 \\
12 \cdot 9 \\
26 \cdot 8 \\
126 \cdot 8\end{array}$ \\
\hline
\end{tabular}

$\mathrm{d}_{\mathrm{o}}$ :registered influenza death rates $(/ 100000)$; $\mathrm{p}$ : vaccine coverage. rates and death rates attributable to influenza with $95 \%$ confidence intervals are presented. From October 1989 to September 1990, the registered pneumonia death rate was 272 per 100000 of which 41 deaths per 100000 were attributed to influenza. Figure 1 shows the registered influenza death rate and the observed pneumonia death rate (dotted lines) with the fitted regression model (upper continuous lines). The grey areas represent the mortality attributable to influenza that has been registered as due to pneumonia. Residuals from the regression model with ARIMA errors are presented below. Four other examples of graphs of monthly registered death rates and the fitted regression models are given in figure 2 . It is evident that the fits between the registered mortality rates and those predicted by the models are close, although the fit seems to be slightly better for pneumonia than for other causes.

The same method has been applied to the models of all the causes of death considered. Only one of the models (for chronic obstructive pulmonary disease (COPD)) yielded a mean of the residuals significantly different from zero (mean $=-0.28 ; p=0.046)$. The inclusion of a constant term in the regression equation for COPD corrected this problem, but did not affect either the estimates attributable to influenza death rates or the goodness of fit tests. Since the constant term added was itself not significantly different from zero, we decided to keep the original model for COPD.

The number of deaths attributable to influenza ranged from $0.5(1988-89)$ to 8.2 (1984-85) times the number of deaths registered as due to influenza alone (table 3 ). Detailed examination showed that deaths attributable to influenza were especially important for respiratory diseases, cardiovascular diseases, and chronic renal failure, but less so for diabetes mellitus and lung cancer. No deaths attributable to influenza were found for breast cancer or cirrhosis. The absence of cases found in chronic rheumatic disease, however, seems more surprising. If we focus on the five years of high mortality, between $23 \%$ and $32 \%$ of the deaths attributable to influenza were registered as deaths from lung diseases, $31 \%$ to $47 \%$ as deaths from heart disease, and $11 \%$ to $13 \%$ from other conditions documented as entailing the risk of death from influenza Similarly, $7 \%$ to $10 \%$ of deaths attributable to influenza were found in unspecified or unknown causes, and $18 \%$ to $25 \%$ in "others" (difference between total mortality and all other causes listed in table 1). The total influenza death rate was finally estimated to be between 28 per 100000 and 482 per 100000 , accounting for 0.3 to $5.2 \%$ of the total mortality among people 75 years old or more.

ESTIMATION OF THE DEATH RATES AVOIDED THROUGH VACCINATION

If we consider only the registered influenza deaths, the death rate avoided through vaccination varied from 3 per 100000 to 127 per 100000 (table 4). When taking into account all the deaths attributable to influenza, the number of deaths avoided may have ranged 

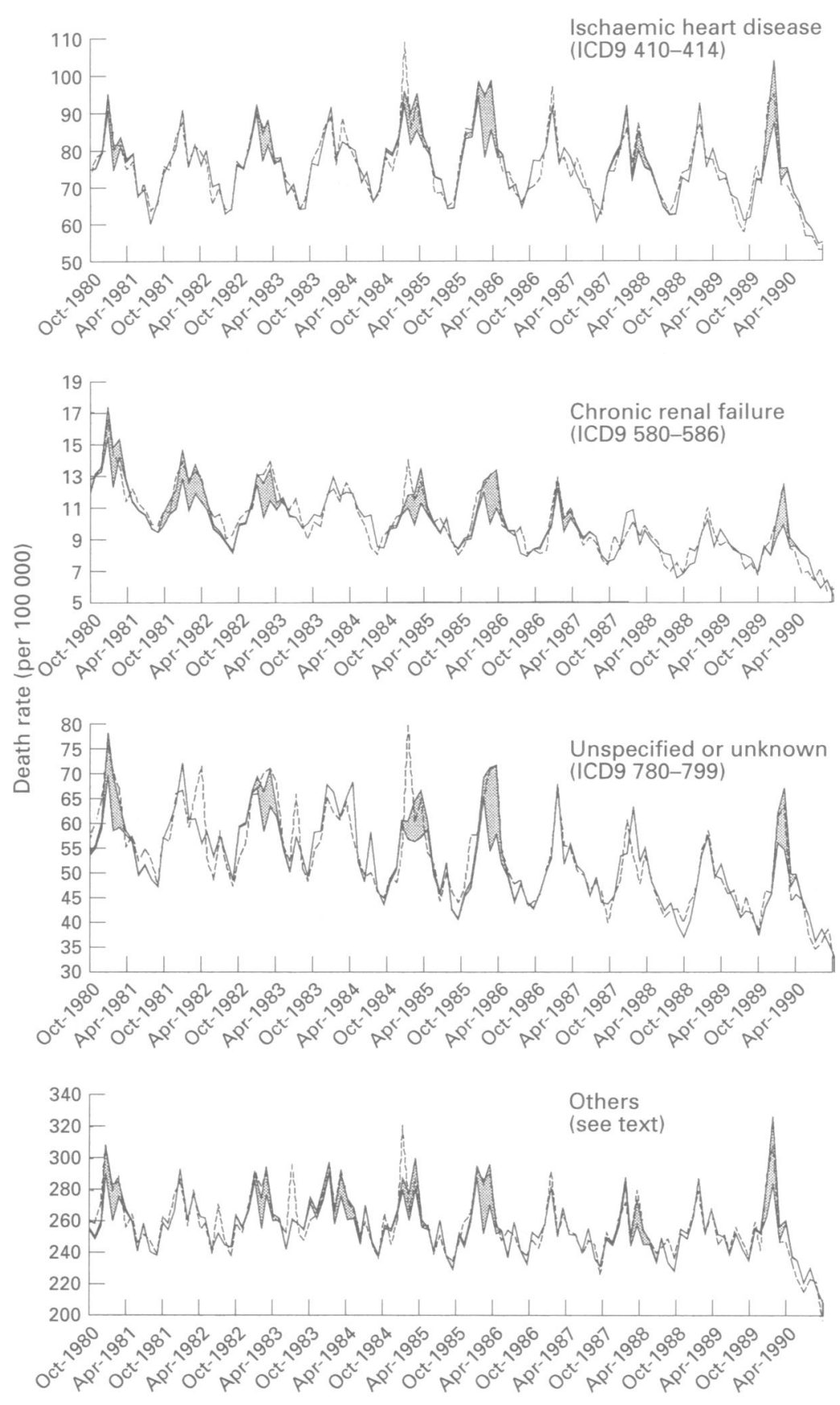

Month (y)

Figure 2 Monthly death rates among people aged 75 years old or older, France, 1980-90. (--) Registered; (upper-) predicted with a regression model including ARIMA errors; (lower ) predicted in absence of influenza. The grey areas represent the part of the death rate attributable to influenza.

Table 5 Estimates of the total influenza death rates per 100000 (including deaths reported as influenza) avoided through vaccination among the elderly $\left(d_{a}\right)$ for different rates of vaccine effectiveness

\begin{tabular}{|c|c|c|c|c|c|c|}
\hline \multirow[b]{2}{*}{ Year } & \multirow[b]{2}{*}{$d_{o}$} & \multirow[b]{2}{*}{$p$} & \multicolumn{4}{|c|}{ Vaccine effectiveness } \\
\hline & & & $\begin{array}{l}40 \% \\
d_{a}\end{array}$ & $\begin{array}{l}60 \% \\
d_{a}\end{array}$ & $\begin{array}{l}80 \% \\
d_{a}\end{array}$ & $\begin{array}{l}90 \% \\
d_{a}\end{array}$ \\
\hline $\begin{array}{l}1981 / 82 \\
1982 / 83 \\
1983 / 84 \\
1986 / 87 \\
1988 / 89 \\
1989 / 90\end{array}$ & $\begin{array}{r}35 \cdot 1 \\
291 \cdot 6 \\
126 \cdot 2 \\
41 \cdot 4 \\
28 \cdot 2 \\
378 \cdot 8\end{array}$ & $\begin{array}{l}0 \cdot 43 \\
0 \cdot 49 \\
0 \cdot 58 \\
0 \cdot 60 \\
0 \cdot 66 \\
0 \cdot 72\end{array}$ & $\begin{array}{r}7 \cdot 3 \\
71 \cdot 1 \\
38 \cdot 1 \\
13 \cdot 1 \\
10 \cdot 1 \\
153 \cdot 2\end{array}$ & $\begin{array}{r}12 \cdot 2 \\
121 \cdot 4 \\
67 \cdot 4 \\
23 \cdot 3 \\
18 \cdot 5 \\
288 \cdot 1\end{array}$ & $\begin{array}{r}18 \cdot 4 \\
188 \cdot 0 \\
109 \cdot 2 \\
38 \cdot 2 \\
31 \cdot 5 \\
514 \cdot 6\end{array}$ & $\begin{array}{r}22 \cdot 2 \\
230 \cdot 0 \\
137 \cdot 8 \\
48 \cdot 6 \\
41 \cdot 3 \\
697 \cdot 3\end{array}$ \\
\hline
\end{tabular}

$\mathrm{d}_{\mathrm{o}}$ :total influenza death rates $(/ 100000)$; $\mathrm{p}$ : vaccine coverage. from 7 per 100000 in $1981-82$ to 697 per 100000 in 1989-90, depending on the intensity of the epidemic, the level of vaccine coverage, and the hypothetical vaccine effectiveness (table 5). For example, if vaccine effectiveness were $60 \%$ in $1989-90$, an estimated 52 per 100000 registered influenza deaths and 288 per 100000 total influenza deaths would have been avoided through vaccination.

\section{Discussion}

This analysis extends previous efforts to evaluate the usefulness of influenza vaccination among the elderly.

\section{ESTIMATION OF THE TOTAL INFLUENZA DEATH RATES}

Our results indicate that between 1000 and 17000 elderly people died from influenza each year in France. Most of these deaths were not registered as being caused by influenza but rather as a result of other underlying conditions.

Estimation of the total influenza death rates relies on the prior hypothesis that a proportion of the various registered death rates in the elderly (for example the pneumonia death rate) may be attributed to influenza, especially during the peak of registered influenza mortality. We could not, however, exclude the possibility that a confounding factor, such as a meteorological or environmental factor, may have acted simultaneously on the death rates creating simultaneous increases in the number of influenza and pneumonia deaths. If so, it would not be possible to determine whether a death registered as pneumonia that occurred during a peak of mortality should be attributed to the confounder or to influenza (which, in this case, would itself be attributed to the confounder). Nevertheless, we believe that it is unlikely that a confounder could explain the link between registered influenza and other registered causes of death. There are no known meteorological, environmental, or other factors that could explain increases in mortality above the seasonal level over periods of two to four months. On the contrary, there is evidence of striking similarities in the form, the amplitude, and the periods of these increases with those of the registered influenza mortality (see for example fig 1 in 1981-82, 1986-87, or 1989-90). It would also be difficult to hypothesize that a confounder could have led to the same bias in other distant countries in which similar results in mortality not registered as influenza but attributable to this illness were reported during documented influenza epidemics. ${ }^{57810}$

Two types of method have been used in other studies to estimate the total influenza mortality. The first is based on computing the number of deaths observed above a seasonal baseline which coincides with influenza epidemics (the so called "excess mortality"). In these studies, influenza mortality rates in people 65 years or older have been found to range from 20 per 100000 to 180 per 100000 during epidemics. ${ }^{156}$ Our findings suggest higher mortality rates, possibly because we have studied an older age group and because our estimates 
include baseline mortality rates and take the whole year into account. The second method for estimating influenza mortality relies on calculating deaths that are not registered as being caused by influenza but are attributable to influenza using regression models. ${ }^{4710} \mathrm{We}$ have developed a regression method that incorporates time series components to eliminate the possibility of spurious regression coefficient results caused by time trend, seasonality, or serial correlation among the residuals.

In our analysis, the greatest proportion of death rates attributable to influenza was mainly found in the most commonly encountered categories of high risk disease. Patients with chronic pulmonary, cardiac, or renal diseases and those with diabetes or other endocrine disorders and conditions treated with immunosuppressive agents are more likely to die from influenza. ${ }^{29}$ Moreover, it has been shown in several studies of mortality statistics that influenza has been the cause of death for these underlying chronic conditions, particularly respiratory and cardiovascular diseases. ${ }^{134810}$ An average annual death rate attributable to influenza in respiratory and cardiovascular diseases of 140 per 100000 has been reported in people aged 70 or more between 1967 and 1982 in The Netherlands. ${ }^{7}$ In the epidemic which occurred in the winter of 1989-90 in England and Wales, the number of deaths attributable to influenza was nine times the number of deaths registered as caused by influenza, and accounted for 20000 deaths among people aged 75 and more. ${ }^{8}$ In the same year in The Netherlands, the number of attributable influenza deaths in people aged 70 or more was over three times greater than the number of deaths registered as being caused by influenza, and the total influenza death rate was 235 per $100000 .^{10}$ Of the non-registered cases, $45 \%$ were reported as deaths from heart disease, $25 \%$ from lung disease, and $30 \%$ from other diseases.

Our findings agree with these results. However, there are still many deaths attributable to influenza but associated with conditions not known to entail the risk of death from influenza ("others" or "undefined"). The proportion is $30 \%$ if we focus on years when registered influenza deaths were high. Because age itself increases the risk of dying from influenza, deaths attributable to influenza are probably to be expected among elderly people, whatever their underlying condition might be. It is also the case that many other underlying conditions may contribute to misclassification and increase the risk of death from influenza, as, for example, neurological diseases, which were not specifically analysed in our study. These deaths may have been misclassified because of the incomplete information supplied by the physicians filling in death certificates.

ESTIMATION OF THE DEATH RATES AVOIDED THROUGH VACCINATION

As a second objective of our analysis, we have developed formulas to estimate the death rates avoided through vaccination. An important as- sumption in our analysis was that the attack rate among unvaccinated subjects did not depend on vaccine coverage. Although there are no data to suggest differences in attack rates in unvaccinated individuals for various levels of vaccine coverage, there is evidence that the ratio of high risk subjects may be greater among vaccinated people compared with unvaccinated. ${ }^{14}{ }^{16} \mathrm{It}$ is likely also that an increase in vaccine coverage would result in a decrease in the number of infectious subjects, leading to a decrease of the probability of infection for an unvaccinated individual. ${ }^{2425}$ Thus, in the absence of vaccination (that is, vaccine coverage equal to zero) the true number of deaths would be greater than the theoretical estimate provided from constant attack rates among the unvaccinated. This would result in underestimations of the death rates observed in the complete absence of vaccination and of the true death rates avoided through vaccination. Nevertheless, even with a low vaccine effectiveness $(40 \%)$, our results suggest that a large number of influenza deaths have been avoided each year. This number is much larger when all deaths attributable to influenza are included.

This study provides public health decision makers with a method of evaluating the efficiency of preventive strategies, whatever the estimated effectiveness of the vaccine might be. The computation of the rate of avoided illness may be applied to various preventable diseases and epidemiological measures (complications, morbidity or economic data). Note for example, that the same reduction in the number of deaths (half the number observed) might be expected with a vaccine coverage of $50 \%$ and a vaccine efficacy of $66.7 \%$ as with a vaccine coverage of $80 \%$ and a vaccine efficacy of $41.7 \%$. Moreover, an increase in the vaccine coverage from 50 to $60 \%$ would have resulted in a $5 \%$ reduction of the number of deaths observed for a vaccine effectiveness of $40 \%$ (equation 5 of the appendix), whereas a $13 \%$ reduction would be expected for a vaccine effectiveness of $80 \%$.

As for the influenza vaccine, our results indicate that the death rate avoided through vaccination depends largely on the intensity of the underlying epidemic (1981-82 compared with 1989-90). Since forecasting methods are not yet available to predict the size of the next epidemic, it is impossible to estimate in advance the future number of avoidable deaths. Hence, the death rate avoided through vaccination may seem relatively low despite the vaccination programme, particularly if it is compared with the total mortality in this elderly population. However, during the six years for which vaccine coverage data were available, the yearly average number of deaths avoided was at least equal to 1850 (vaccine effectiveness $=40 \%$ ). In our study we did not take into account the benefits of influenza vaccine in terms of the prevention of complications and admissions to hospital. ${ }^{12-16}$ We believe that these results should help to promote annual vaccination among the elderly, while encouraging the development of still more effective influenza vaccines. 


\section{Appendix}

Vaccine effectiveness (VE) is usually defined by $\mathrm{VE}=1-\mathrm{AR}_{\mathrm{v}} / \mathrm{AR}_{\mathrm{u}}{ }^{24}$ where $\mathrm{AR}_{\mathrm{v}}$ and $\mathrm{AR}_{\mathrm{u}}$ are the attack rates of mortality in vaccinated and unvaccinated subgroups respectively.

Let,

- $\mathrm{N}$, be the population subgroup size,

- $\mathrm{n}_{\mathrm{u}}$, be the unvaccinated subgroup size,

- $\mathrm{n}_{\mathrm{v}}$, be the vaccinated subgroup size,

- $\mathrm{p}$, be the vaccine coverage $\left(\mathrm{N} p=\mathrm{n}_{\mathrm{v}} ; \mathrm{N}\right.$ $\left.(1-\mathrm{p})=\mathrm{n}_{\mathrm{u}}\right)$,

- $\mathrm{d}_{\mathrm{o}}$, be the registered to total influenza death rate.

Then,

$$
\begin{aligned}
d_{o} & =\frac{\left(A_{\mathrm{u}} n_{\mathrm{u}}+A R_{\mathrm{v}} \mathrm{n}_{\mathrm{v}}\right)}{\left(\mathrm{n}_{\mathrm{u}}+\mathrm{n}_{\mathrm{v}}\right)} \\
& =\frac{\operatorname{AR}_{\mathrm{u}}\left(\mathrm{n}_{\mathrm{u}}+(1-\mathrm{VE}) \mathrm{n}_{\mathrm{v}}\right)}{\left(\mathrm{n}_{\mathrm{u}}+\mathrm{n}_{\mathrm{v}}\right)}
\end{aligned}
$$

replacing $n_{v} / n_{u}=p /(1-p)$ and simplifying we obtain

$$
\mathrm{d}_{\mathrm{o}}=\mathrm{AR}_{\mathrm{u}}(1-\mathrm{VE} \mathrm{p})
$$

We assume that the attack rate among the unvaccinated does not depend on the level of vaccine coverage, and then, in the absence of vaccination, the death rate is simply equal to $\mathrm{AR}_{\mathrm{u}}$.

The death rate avoided thanks to vaccination $\left(d_{a}\right)$ is given by:

$$
\begin{aligned}
\mathrm{d}_{\mathrm{a}} & =\mathrm{AR}_{\mathrm{u}}-\mathrm{d}_{\mathrm{o}} \\
& =\frac{\mathrm{d}_{\mathrm{o}}}{(1-V E \mathrm{p})}-\mathrm{d}_{\mathrm{o}} \\
& =\frac{\mathrm{d}_{\mathrm{o}} \mathrm{VE} \mathrm{p}}{(1-V E \mathrm{p})}
\end{aligned}
$$

It can easily be shown that the change of the death rate $\left(\triangle_{0}\right)$ in a given year according to the change of the vaccine coverage $\left(\triangle_{p}\right)$, may be estimated by:

$$
\Delta_{\mathrm{o}}=\frac{-\mathrm{d}_{\mathrm{o}} \text { VE } \Delta \mathrm{p}}{(1-\text { VE } \mathrm{p})}
$$

This study is supported by grants from the 'Caisse Nationale d'Assurance Maladie des Travailleurs Salariés'.

We thank F Hatton and E Michel from the Service Commun 8 for supplying data regarding deaths; the staff of the Groupe d'Etude et d'Information sur las Grippe for providing data regarding vaccine coverage; and Professors DS Fedson, UniAntoine, for their most helpful suggestions during the preparation of this manuscript.
1 Alling DW, Blackwelder WC, Stuart-Harris CH. A study of excess mortality during influenza epidemics in the United States, 1968-1976. Am f Epidemiol 1981;113: $30-43$.

2 Barker WH, Mullooly JP. Pneumonia and influenza deaths during epidemics. Implications for prevention. Arch Intern during epidemics. Imp

3 Glezen WP. Serious morbidity and mortality associated with influenza epidemics. Epidemiol Rev 1982;4:25-44.

4 Tillet HE, Smith JWG, Gooch CD. Excess deaths at tributable to influenza in England and Wales: age at death and certified cause. Int $\mathcal{F}$ Epidemiol 1983;12:344-52.

5 Lui K-J, Kendal AP. Impact of influenza epidemics on mortality in the United States from October 1972 to May 1985. Am ₹ Public Health 1987;77:712-16.

6 Stroup DF, Thacker SB, Herndon JL. Application of multiple time series analysis to the estimation of pneumonia and influenza mortality by age 1962-1983. Stat Med 1988 and influenza

7 Sprenger MJW, Van Naelten MAMG, Mulder PGH, Masurel N. Influenza mortality and excess deaths in the elderly, 1967-1982. Epidemiol Infect 1989;103:633-41.

8 Curwen M, Dunnell K, Ashley J. Hidden influenza deaths: 1989-1990. Population Trends 1990;61:31-3.

9 Nicholson KG. Influenza vaccination and the elderly. BMF 1990;301:617-18.

10 Sprenger MJW, Mulder PGH, Beyer WEP, Van Strik R, Masurel N. Impact of influenza on mortality in relation to age and underlying disease, 1967-1989. Int $\mathcal{f}$ Epidemiol $1993 \cdot 22: 334-40$.

11 Saah AJ, Neufeld R, Rodstein M, La Montagne JR, Blackwelder WC, Gross P, Quinnan G, Kaslow RA. Influenza vaccine and pneumonia mortality in a nursing home population. Arch Intern Med 1986;146:2353-7.

12 Arden NH, Patriarca PA, Kendal AP. Experiences in the use and efficacy of inactivated influenza vaccine in nursing homes. In: Kendall AP, Patriarca PA, eds. Options for the control of influenza New York: AR Liss, 1986:155-68.

13 Strassburg MA, Greenland S, Sorvillo FJ, Leib LE, Habel LA. Influenza in the elderly: report of an outbreak and a review of vaccine effectiveness reports. Vaccine 1986;4: $38-43$.

14 Foster DA, Talsma A, Furumoto-Dawson A, Ohmit SE Margulies JR, Arden NH, Monto AS. Influenza vaccine effectiveness in preventing hospitalization for pneumonia in the elderly. Am $\mathcal{F}$ Epidemiol 1992;136:296-307.

15 Carrat F, Valleron A-J. Le vaccin antigrippal. Revue bibliographique. (In French). Rev Mal Respir 1994;11:239-

16 Nichol KL, Margolis KL, Wuorenma RN, Von Sternber $T$. The efficacy and cost effectiveness of vaccination against influenza among elderly persons living in the community. influenza among elderly persons

17 Box GEP and Jenkins GM. Time series analysis. Forecastin and control. Rev ed. San Francisco: Holden Day, 1976.

18 Choi K, Thacker SB. An evaluation of influenza mortality surveillance. 1962-1979. I. Time series forecasts of expected pneumonia and influenza deaths. $A m \mathcal{F}$ Epidemiol 1981;113:215-26.

19 Helfenstein U. Bok-Jenkins modelling of some viral infectious diseases. Stat Med 1986;5:37-47.

20 Katzoff $M$. The application of time series forecasting methods to an estimation problem using provisional mormethods to an estimation problem using
tality statistics. Stat Med 1989;8:335-41.

21 Helfenstein U. The use of transfer function models, in tervention analysis and related time series methods in epidemiology. Int $\mathcal{F}$ Epidemiol 1991;20:808-15.

22 Harvey AC, Phillips GDA. Maximum likelihood estimation of regression models with autoregessive-moving average disturbance. Biometrika 1979;66:49-58.

23 Ljung GM, Box GEP. On a measure of lack of fit in time series models. Biometrika 1978;65:297-303.

24 Halloran ME, Haber M, Longini IM, Struchiner CJ. Direct and indirect effects in vaccine efficacy and effectiveness. Am 7 Epidemiol 1991;133:323-31.

25 Halloran ME, Struchiner CJ. Study designs for dependent happenings. Epidemiology 1991;2:231-8. 